\title{
PERANCANGAN SOFTWARE ASISTEN DOSEN SEBAGAI MEDIA DALAM PELAKSANAAN COMPUTER ASSISTED LEARNING DI AMIK INDONESIA BANDA ACEH
}

\author{
Lukman Ahmad ${ }^{1}$, Muhammad Wali ${ }^{2}$ \\ E-mail: lukmanahmad@amikindonesia.ac.id, muhammadwali@amikindonesia.ac.id \\ D-III Manajemen Informatika AMIK Indonesia \\ L. Teuku Nyak Arif, Simpang Krueng Raya, Banda Aceh, Aceh. Tlpn/ Fax : (0651) 52043
}

\begin{abstract}
Abstrak
Dalam suatu perkuliahan, seorang dosen adalah manajer yang bertanggung-jawab untuk mengelola segala sumberdaya yang ada untuk tercapainya tujuan pembelajaran. Pada skala yang lebih besar, suatu perguruan tinggi harus mampu mengelola semua sumberdaya yang dimiliki secara efektif dan efesien dalam upaya menghasilkan lulusan yang berkualitas. Bahan-bahan ajar dan metode penyajiannya adalah sumberdaya yang harus dikelola. Sekarang ini bahan ajar sudah banyak yang berformat digital dan multimedia. Dan Para dosen pun sudah lazim menggunakan komputer (notebook) dalam mempresentasikan materi ajarnya. Namun aplikasi untuk membuat presentasi masih belum banyak pilihan. Dibutuhkan software yang berfungasi sebagai media pembelajaran, yang mudah diopersionalkan. Penelitian ini mencoba untuk memberikan solusi dengan merekayasa perangkat lunak yang berfungsi sebagai media pembelajaran, sebagai sarana yang dapat memuat dan menayangkan semua bahan ajar digital dan multimedia.. Perangkat lunak tersebut dapat diaplikasikan secara stand alone (off line) dan juga mampu beroperasi dalam jaringan kampus (online). Metode dan model perancangan software dalam penelitian ini digunakan function data methods dan waterfall model. Hasil dari penelitian ini adalah prototypt software "Asisten_Dosen", yang akan diujikembangkan sebagai media Pembelajaran Berbantuan Komputer (Computer Asissted Learning) di AMIK Indonesia Banda Aceh.
\end{abstract}

Kata kunci: Perancangan, Media Pemebelajaran, Computer Asissted Learning

\section{Pendahuluan}

Teknologi informasi dan komputer sudah lazim digunakan dalam proses belajar mengajar. Bahkan bahan-bahan ajar pun sekarang ini sudah banyak yang berformat digital. Sementara itu, seorang dosen/tenaga pengajar adalah seorang manager di dalam ruang kelasnya, dituntut agar mampu memanfaat bahan-bahan ajar tersebut secara efektif dan efesien. Untuk itu diperlukan model pembelajaran Pembelajaran Berbantuan Komputer (Computer Asissted Learnig). Sebagai model pengajaran, CAL telah dikenal dan digunakan sejak tahun 60-an, dalam penerapannya terus berkembang seiring dengan perkembangan teknologi. Untuk dapat diimplementasikan model CAL membutuhkan hardware, software dan brainware. Di AMIK Indonesia Banda Aceh, para dosennya masing-masing sudah memiliki komputer laptop (notebook), dan biasa digunakan untuk media presentasi materi kuliah. Namun software untuk membuat presentasi masih sangat terbatas. Sehingga proses pembuatan, penyimpanan dan penyajian bahan ajar yang berformat digital dan multimedia dilakukan kurang efesien dan tidak efektif.
Pada skala yang lebih besar pada tingkat Perguruan Tinggi (kampus) diperlukan pengelolaan materi ajar yang sesuai dengan kurikulum. Perguruan tinggi harus mampu menjamin ketersediaan bahan ajar dan memonitoring pemberian materi kuliah sesuai dengan kurikulum yang ditetapkan. Oleh sebab itu diperlukan peran perpustakaan yang dapat mewadahi dan memenuhi kebutuhan tersebut.

Penelitian ini mencoba memberikan solusi dari permasalan diatas, yaitu dengan membuat system pendukung berupa software yang dapat berfungsi sebagai media untuk pelaksanaan Computer Asissted Learnig (CAL) yang mudah untuk dimodifikasi oleh dosen, dapat dioperasikan secara online dalam area jaringan kampus, atau juga hanya personal (offline) oleh masing-masing dosen /tenaga pengajar, serta terintegrasi dengan system operasional perpustakaan agar dapat dikelola dengan baik.

\section{Media Pembelajaran}

Menurut Azhar Arsyad dalam bukunya mengatakan [Azhar Arsyad:1]: "Media berasal dari bahasa latin merupakan bentuk jamak dari "Medium" yang secara harfiah berarti "Perantara" 
atau "Pengantar" yaitu perantara atau pengantar sumber pesan dengan penerima pesan". Sarana pendidikan yang digunakan sebagai perantara dengan menggunakan alat penampil dalam proses belajar mengajar untuk mempertinggi efektivitas dan efisiensi pencapai tujuan instruksional, meliputi kaset, slide, dan gambar. Jadi media pembelajaran adalah segala jenis sarana pendidikan yang digunakan sebagai perantara dalam proses belajar mengajar untuk meningkatkan efektivitas dan efisiensi pencapaian tujuan instruksional mencakup media grafis termasuk gambar, media yang menggunakan alat penampil, peta, model, globe, dan sebagainya. Media instruksional edukatif mencakup perangkat lunak (software) dan perangkat keras (hardware) yang berfungsi sebagai alat bantu.

\section{CAL (Computer Asissted Learnig)}

CAL adalah suatu model pengajaran dengan metode yang memanfaatkankan komputer sebagai media penyampaian materi ajarnya dalam proses pembelajaran. Taksonomi penggunaan komputer dalam bidang pendidikan yang paling banyak digunakan. Klasifikasikan penggunaan komputer dalam pendidikan menjadi 3 (tiga) kelompok, yaitu komputer sebagai tutor, komputer sebagai tool, dan computer sebagai tutee. [Rustam:2]

Komputer sebagai "tutor" dimaksudkan untuk menjelaskan peran komputer sebagai alat untuk menyajikan materi pembelajaran yang diprogram secara elektronik. Komputer sebagai "tool" menjelaskan fungsi komputer yang amat luas sebagai alat bantu, agar pekerjaan menjadi lebih cepat dan lebih efisien, misalnya, administrasi biaya pendidikan, administrasi nilai, administrasi perpustakaan, dan administrasi lainnya. Dan klasifikasi komputer sebagai "tutee" berarti komputer sebagai obyek untuk dikontrol melalui pemrograman, agar mampu memecahkan masalah.

Pembelajaran berbasis komputer adalah cara untuk memproduksi atau menyajikan materi dengan menggunakan sumber berbasis mikroprosesor (komputer). Pembelajaran berbasis komputer termasuk dalam klasifikasi komputer sebagai tutor. Akan tetapi perkembangan aplikasi computer dalam pendidikan menunjukkan bahwa pembelajaran berbasis komputer sudah menambahkan tool kedalam paket aplikasinya, sehingga perbedaan penggunaan komputer dalam pendidikan sebagai tutor dan penggunaan komputer dalam pendidikan sebagai tool menjadi semakin kabur.

\section{Metode Penelitian}

Jenis penelitian ini adalah penelitian dan pengembangan atau research and development (R\&D) Dalam Penelitian ini dikembangkan produk berupa software untuk sarana pendukung CAL di AMIK Indonesia Banda Aceh.

Dalam pengembangan /perancangan perangkat lunak pada menelitian ini digunakan metode fungsi /data (function data methods). Menurut DeMarco [DeMarco:3]. Dalam metodologi ini, hal yang utama adalah membuat spesifikasi dan dekomposisi sistem secara fungsional. Metode fungsi /data membedakan fungsi dan data. Fungsi, pada prinsipnya, adalah aktif dan memiliki perilaku, sedangkan data adalah pemegang informasi pasif yang dipengaruhi oleh fungsi. Sistem biasanya dipilah menurut fungsi, di mana data dikirim di antara fungsi-fungsi tersebut. Fungsi kemudian dipilah lebih lanjut dan akhirnya diubah menjadi kode sumber (program komputer). Sedangkan model perancangan software yang digunakan dalam penelitian ini adalah model air terjun (Waterfall Model.). Menurut Pressman, model "Waterfal"l atau "Linear Sequential Model" atau sering juga disebut dengan "classic life cycle", adalah model klasik yang bersifat sistematis, berurutan dalam membangun software. Disebut dengan waterfall karena tahap demi tahap yang dilalui harus menunggu selesainya tahap sebelumnya dan berjalan berurutan. [Pressman:4] Tahap - tahap dalam Waterfall Model menurut Pressman:

a. Communication (Project Initiation \& Requirements Gathering) Sebelum memulai pekerjaan yang bersifat teknis, sangat diperlukan adanya komunikasi dengan user demi memahami dan mencapai tujuan yang ingin dicapai. Hasil dari komunikasi tersebut adalah inisialisasi proyek, seperti menganalisis permasalahan yang dihadapi dan mengumpulkan data-data yang diperlukan, serta membantu mendefinisikan fitur dan fungsi software. Pengumpulan data-data tambahan bisa juga diambil dari jurnal, artikel, dan internet.

\section{b. Planning (Estimating, Scheduling, Tracking)}

Tahap berikutnya adalah tahapan perencanaan yang menjelaskan tentang estimasi tugas-tugas teknis yang akan dilakukan, resiko resikoyang dapat terjadi, sumber daya yang diperlukan dalam membuat sistem, produk kerja yang ingin dihasilkan, penjadwalan kerja yang akan dilaksanakan, dan tracking proses pengerjaan sistem. 
c. Modeling (Analysis \& Design)

Tahapan ini adalah tahap perancangan dan permodelan arsitektur sistem yang berfokus pada perancangan struktur data, arsitektur software, tampilan interface, dan algoritma program. Tujuannya untuk lebih memahami gambaran besar dari apa yang akan dikerjakan.

\section{d. Construction (Code \& Test)}

Tahapan Construction ini merupakan proses penerjemahan bentuk desain menjadi kode atau bentuk/bahasa yang dapat dibaca oleh mesin. Setelah pengkodean selesai, dilakukan pengujian terhadap sistem dan juga kode yang sudah dibuat. Tujuannya untuk menemukan kesalahan yang mungkin terjadi untuk nantinya diperbaiki.

\section{e. Deployment (Delivery, Support, Feedback)}

Tahapan Deployment merupakan tahapan implementasi software ke customer, pemeliharaan software secara berkala, perbaikan software, evaluasi software, dan pengembangan software berdasarkan umpan balik yang diberikan agar sistem dapat tetap berjalan dan berkembang sesuai dengan fungsinya.

Kemudian untuk teknis pemograman dalam penelitian ini, digunakan bahasa pemograman yang digunakan adalah HTML (Hypertext Markup Language), karena untuk memudahkan dalam operasional secara jaringan (offline), dan mampu untuk menayangkan teks, gambar, animasi (GIF), audio dan video dan satu halaman. Pertimbangan lain adalah lembar HTML dapat dioperasikan oleh semua operating system, serta mudah untuk dimodifikasi walaupun dengan program pengolah kata (Ms Word) saja.

Menurut Edy Winarno [Edy Winarno:5] HTML adalah sebuah bahasa markah yang digunakan untuk membuat sebuah halaman web, menampilkan berbagai informasi di dalam sebuah penjelajah web Internet dan pemformatan hiperteks sederhana yang ditulis dalam berkas format ASCII agar dapat menghasilkan tampilan wujud yang terintegerasi. Dengan kata lain, berkas yang dibuat dalam perangkat lunak pengolah kata dan disimpan dalam format ASCII normal sehingga menjadi halaman web dengan perintahperintah HTML.

\section{Hasil dan Pembahasan}

Langkah-langkah dan hasil penelitian ini adalah sebagai berikut:
(1) Communication
(Project
Initiation \& Requirements Gathering).

pertama, bertujuan mengetahui spesifikasi kebutuhan dan analisis. Peneliti melakukan wawancara langsung ke AMIK Indonesia dengan simpulan sebagai berikut:

a. Pihak dosen /tenaga pengajar membutuhkan software untuk melakukan presentasi bahan ajar yang mudah dimodifikasi, dan mudah dioperasikan. Asumsi "mudah" disini adalah semudah mengetik dengan Ms Word dan untuk menyajikan presentasi semudah mem"browsing" situs internet.

b. Pihak mahasiswa membutuhkan suana belajar yang menarik, penyajian materi kuliah mereka sukai adalah berupa visualisasi dan multimedia.

c. Pihak akademik dan perpustakaan membutuhkan software untuk mengelola bahan-bahan ajar yang berformat digital, dan kemudahan untuk didistribusikan dalam jaringan computer kampus.

(2) Planning (Estimating, Scheduling, Tracking) Kemudian berdasarkan spesifikasi kebutuhan, dilakukan analisa sehingga mendapatkan simpulan yang baru, yaitu:

a. Setiap dosen /tenaga pengajar dapat diberikan semacam paket berupa template yang mudah diisi bahkan dengan hanya menggunakan $M s$ Word. Namun paket tersebut berformat HTML agar dapat bekerja dalam jaringan karena memudahkan untuk diintegrasikan dengan system yang ada di computer server perpustakaan.

b. Laman Index ditempatkan di server pustakan, laman tersebut harus mampu memuat semua file template yang sudah diisi oleh para dosen. Server pustaka menjadi tempat penyimpanan semua bahan ajar yang telah dimuat oleh para dosen dalam template yang diberikan tersebut.

(3) Modeling (Analysis \& Design) Dari hasil Perencanaan penelitian dilanjutkan dengan membuat beberapa modul /prototype purwarupa berikut

$\checkmark$ Modul /Paket software media pembelajaran, untuk para dosen (for client)

$\checkmark$ Sistem Index untuk perpustakaan (for server)

(4) Construction (Code \& Test). Setelah rancangan diselesaikan kemudian dilakukan implementasi modul. Modul-modul ini pertama-tama diuji secara sendiri-sendiri dan kemudian secara bersama-sama. 
(5) Deployment (Delivery, Support, Feedback). Adalah tahap implementasi serta dilakukan proses pengintegrasi system dengan proses aktivitas perkuliahan di AMIK Indonesia. Membagikan template dan tutorial pengisiannya. Memasang system pendukung untuk pengelolaang atau Laman Index di server pustaka sekaligus melatih petugas pustaka sebagai administrator sisyem tersebut

\section{Konsep Perancangan Software}

Berdasarkan kebutuhan dan kondisi yang ada di lokasi penelitian, maka dapat digambarkan sebuah pola kerja sederhana seperti yang tergambar pada skema berikut:

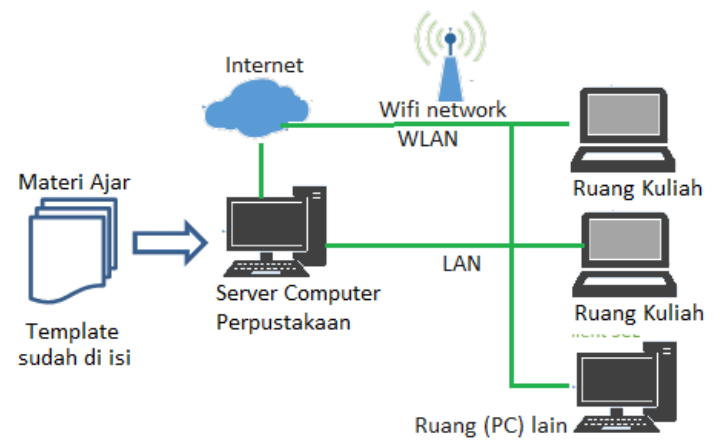

Gambar 1. Konsep Arsitektur network Sumber: Hasil penelitian (2018)

\section{Keterangan:}

- Laman-laman template yang sudah diisi dimuat ke komputer server pustaka yang sudah dipasang sistem aplikasi Asisten_Dosen

- Kemudian dibagikan melalui jaringan ke ruang kuliah untuk digunakan dalam pemberian materi /perkuliahan.

\section{Desain Laman Index}

Fungsi utama dari laman ini adalah sebagai sarana untuk memuat (Embed) semua file HTML yang ada dalam folder tersebut.

Halaman ini ditempatkan dalam server pustaka, yaitu pada folder

\section{CAL-SS_AMIK/system/}

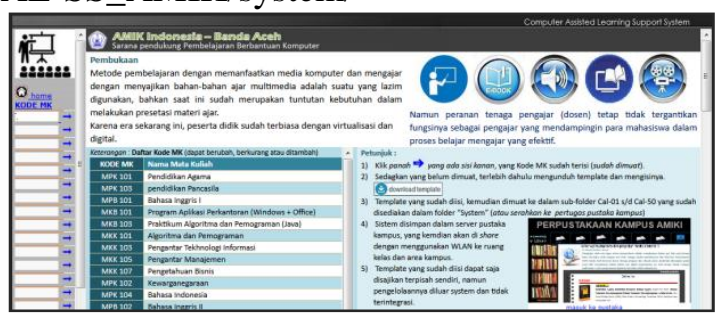

Gambar 2. Halaman Awal

Sumber: hasil penelitian (2018)
File pendukung laman index ada 4 (emapt) yaitu: menu.html, body.html, footer.html dan head.html. Teknik pengkodeannya adalah dengan fungsi iframe dan frame set untuk memanggil setiap file yang ada pada masing-masing sub folder, sehingga dapat membuka file Asisten_Dosen.html secara terintegrasi.

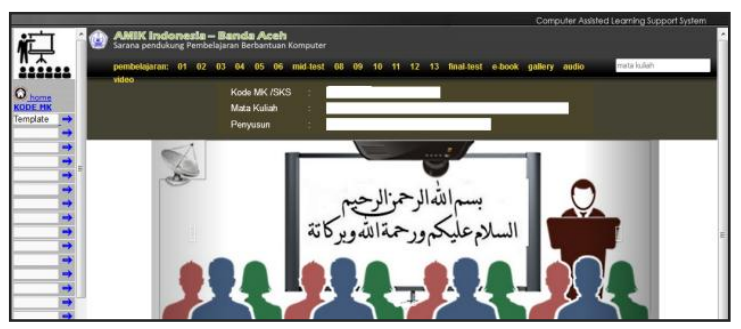

Gambar 3. Halaman Asisten Dosen Sumber: hasil penelitian (2018)

\section{Desain File Template HTML}

Fungsi file tamplete dalam hal ini adalah sebagai file yang akan dimodifikasi oleh para dosen dengan memuat bahan ajar yang berupa teks, gambar, animasi, PDF, audio dan video. Agar sesuai dengan kebutuhan maka disediakan menu yang berisikan.

Namun harap diingat karena perancangan software dalam penelitian ini menggunakan metode fungsi /data (function data methods), yang memberlakukan fungsi dan data secara terpisah. Maka penempatan file dalam direktori harus benar-benar diperhatikan.

(1) Lembar awal dari paket software Asisten dosen berisikan form mata kuliah, kode mata kuliah, nama penyusun (dosen)

Ditempatkan pada Direktori:

(drive aktif): /CAL

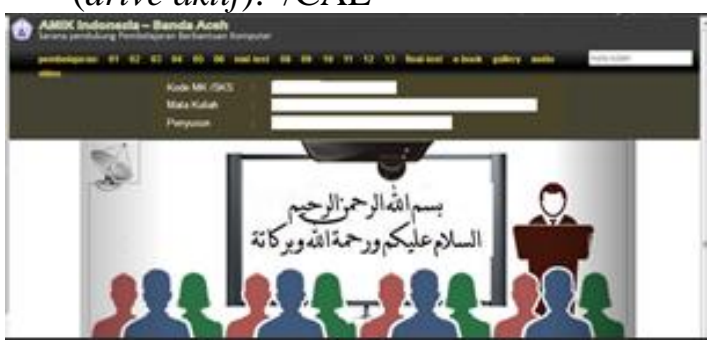

Gambar 4. Lembar depan Asisten Dosen Sumber: hasil penelitian (2018)

(2) Lembar untuk menulis bahan ajar, file ini dapat dimodifikasi dengan menggunakan Ms Word saja, sekaligus dalam hal memuat table, bagan /gambar, animasi dan grafik. Sehingga menudahkan pengguna. Untuk sekali pertemuan kuliah diberi 1 (satu) laman, jadi tersedia 13 laman untuk pertemuan kuliah dan 
2 laman untuk penyajian soal (ujian tengah semester dan ujian akhir semester)

Ditempatkan pada sub direktori:

(drive aktif): /CAL /Presentasi/01

(drive aktif): /CAL /Presentasi/02

(drive aktif): /CAL /Presentasi/04

(drive aktif): /CAL /Presentasi/04

(drive aktif): /CAL /Presentasi/05

(drive aktif): /CAL /Presentasi/06

(drive aktif): /CAL /Presentasi/07

(drive aktif): /CAL /Presentasi/08

(drive aktif): /CAL /Presentasi/09

(drive aktif): /CAL /Presentasi/10

(drive aktif): /CAL /Presentasi/11

(drive aktif): /CAL /Presentasi/12

(drive aktif): /CAL /Presentasi/13

(drive aktif): /CAL /Presentasi/Test-Midle

(drive aktif): /CAL /Presentasi/ Test-Final

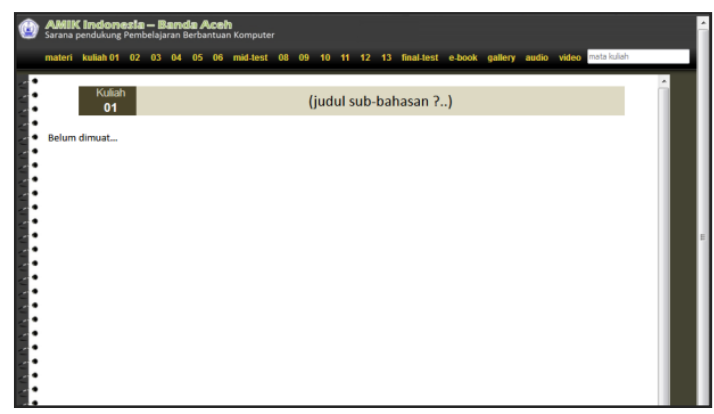

Gambar 5. Lembar pengetik bahan ajar

Sumber: hasil penelitian (2018)

(3) Lembar untuk memuat audio dan lembar untuk memuat video.

Ditempatkan pada sub direktori:

(drive aktif): /CAL /Presentasi/Audio

(drive aktif): /CAL /Presentasi/Video
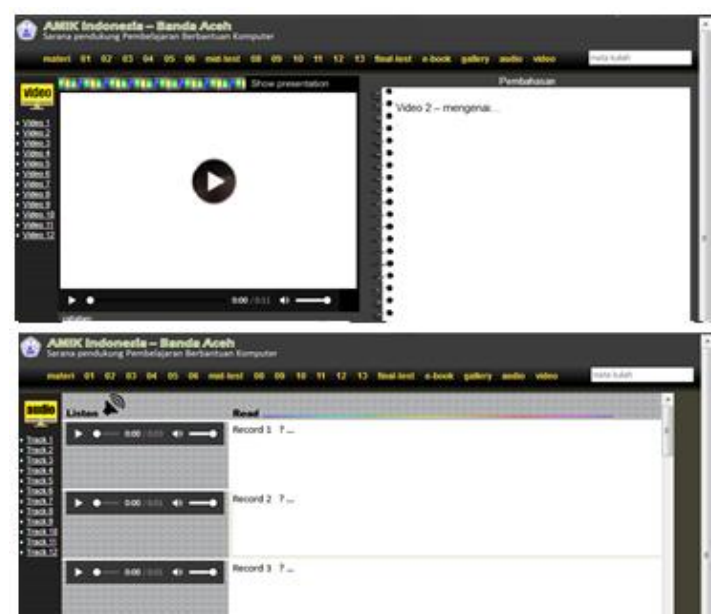

Gambar 6. Lembar Audio dan Video Sumber: hasil penelitian (2018)
Setiap video dan audio dalam penayangannya didampingi text box untuk diisi dengan tulisan agar dosen dapat mengetik intruksi, keterangan atau kesimpulan. Modifikasi dapat dengan menggunakan Ms Word.

- Laman video disediakan 5 lembar dan 1 lembar kumpulan video.

- Laman audio disediakan 12 lembar dan 1 lembar kumpulan audio

(4) Laman galeri untuk memuat album foto /gambar

Ditempatkan pada sub direktori:

(drive aktif): /CAL /Presentasi/Gallery

(5) Laman e-books, untuk kumpulan file PDF sekaligus dengan reader pdf yang memang sudah terintegrasi secara play-in pada program browsing internet yang ada sekarang ini.

Laman ini ditempatkan pada:

(drive aktif): /CAL /Presentasi/PDF

\section{Syarat Operasional}

Pembangunan system software ini membutuhkan perangkat keras sebagai berikut: untuk client diperlukan CPU computer atau notebook minimal setingkat dual core; 1 unit CPU untuk server di perpustakaan minimal setingkat core duo; seperangkat peripheral untuk jaringan baik yang nirkabel (wirelass) atau cukup dengan menggunakan kabel UTP; Sedangkan untuk melakukan presentasi di ruang kelas disediakan projector dan sound system sederhana.

Sedangkan program-program software yang minimal harus dimiliki agar pengoperasian paket ini adalah:

- Sistem operasi Ms Windows (versi 7 ke atas), Mac, atau Linux

- Program browsing internet yang sudah play-in untuk membaca file PDF, dan multimedia player (sudah didukung dengan adobe player)

Kemudian untuk keperluan editing dan modifikasi bahan digital juga sebaiknya dilengkapi dengan program aplikasi pendukung berikut:

- Program aplikasi untuk recorder dan editor audio, seperti program Audacity atau aplikasi lain yang sejenis.

- Program aplikasi video converter

- Program aplikasi untuk mendesain gambar dan program untuk pembuatan animasi. 


\section{Kesimpulan}

Dari hasil penelitian ini, diperoleh beberapa kesimpulan, bahwasanya:

a. Hasil dari rekayasa perangkat lunak pada penelitian ini diberi nama "Asisten Dosen" karena diharapkan dapat berfungsi sebagai media pembelajaran.

b. Lembar HTML dapat dimanfaatkan sebagai media untuk presentasi materi ajar. Karena sangat efektif untuk menayangkan bahanbahan ajar yang berupa teks, gambar, animasi, audio dan video. Dan lembar HTML dapat dioperasikan secara online maupun offline. Dan seteleh dimodifikasi sedemian rupa file template yang berformat html sangan mudah untuk diisi /edit oleh dosen (user) karena cukup dengan program Ms Word saja.

c. Namun karena pengkodean HTML bukanlah DBMS (Data Base Management System) maka metode perancangan dalam penelitian ini adalah dengan cara fungsi /data (function data methods). Hal ini dimaksud untuk mengupayakan agar kumpulan lembar HTML yang ada dan yang akan dimuat ke dalam server pustakan dapat terintegrasi menjadi satu kesatuan. Secara teknis kode yang digunakan adalah frame set dan iframe, teknis ini peneliti gunakan untuk melakukan pemuatan (embed) lembar html dengan html yang lain menjadi satu lembar, selain itu juga didukung dengan penggunaan table dan pengkodean yang sesuai kebutuhan desain

d. Karena metode fungsi /data membedakan fungsi dan data. Fungsi, pada prinsipnya, adalah aktif dan memiliki perilaku, sedangkan data adalah pemegang informasi pasif yang dipengaruhi oleh fungsi. e. Jadi peneliti memilah sistem menurut fungsi, di mana data dikirim di antara fungsi-fungsi tersebut. Fungsi kemudian dipilah lebih lanjut dan akhirnya diubah menjadi kode sumber (program software).

f. Pemilahan dibagi berdasarkan direktori (folder) yang terstruktur, data tersimpan dalam folder-folder yang telah ditentukan yang nantinya dipanggil dengan fungsi pengkodean. Dengan demikian pengguna (user) juga harus memahami struktur direktori tempat penyimpanan filenya.

g. Kendala yang timbul adalah bila nama file atau tipe file dalam struktur diubah akan mengakibatkan file tersebut tidak bisa dipanggil. Untuk itu hal ini harus benar-benar dijelaskan kepada user baik dalam kegiatan training user dan harus ditulis dalam buku user's manual.

\section{Daftar Pustaka}

[1] Azhar Arsyad, Media Pembelajaran, PT. Raja Grafindo Persada, 2007.

[2] Rusman, Belajar dan Pembelajaran Berbasis Komputer. Bandung: Alfa Beta, 2012.

[3] DeMarco, Tom, Fundamentals of a Discipline of Computer Program and Systems Design, Yourdon Press, 2014.

[4] Pressman, R.S., Rekayasa Perangkat Lunak: Pendekatan Praktisi Buku I. Yogyakarta: Andi, 2015.

[5] Edy Winarno, Ali Zaki, SmithDev. Pemrograman Web Berbasis HTML5, PHP, dan JavaScript, PT Elex Media Komputindo, Jakarta, 2014. 